Aletria, Belo Horizonte, v. 29, n. 3, p. 151-168, 2019

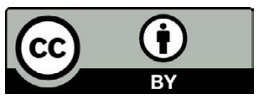

\title{
Por uma crítica literária do Sul global
}

\section{Towards a Literary Criticism of the Global South}

\author{
Fernanda Dusse \\ Centro Federal de Educação Tecnológica de Minas Gerais (CEFET-MG), Belo \\ Horizonte, Minas Gerais / Brasil \\ fernandadusse@gmail.com
}

Resumo: A cooperação Sul-Sul, fundamental para o projeto político de partidos de centro-esquerda no começo deste milênio, é pautada pelo diálogo entre países e pelo respeito à diversidade. Capaz de escapar da totalidade do Estado-nação e do abandono do neoliberalismo, o Sul global, fundado nessas ações políticas transnacionais, foi abraçado por diversos teóricos contemporâneos e passou a figurar como um projeto alternativo de futuro. Considerando isso, o presente trabalho apresenta o conceito de Sul global e debate sobre sua capacidade de modificar a geografia mundial. A seguir, são propostas aproximações entre essas práticas geopolíticas e tendências da crítica literária na contemporaneidade, sugerindo novos caminhos para a teoria da literatura e para a literatura comparada. Nesse sentido, o trabalho tenta preencher a lacuna deixada pelas universidades brasileiras em seu desinteresse por acompanhar o movimento conduzido por líderes políticos do país na primeira década deste século.

Palavras-chave: Sul global; humanidades; literatura comparada; cooperação.

\begin{abstract}
South-South cooperation has oriented the political project of center-leftist parties during the first years of this millennium as it is based on diversity and dialogues among nations. Founded by these transnational political actions, the global South is able to escape the totality of the State and the abandonment of neoliberalism, thus it has been embraced by many contemporary theorists as a project of an alternative future. This essay presents the concept of the global South and debates upon its capacity to change the world's geography. The geopolitical practices are then brought closer to trends in contemporary literary criticism in order to suggest new paths for the fields of
\end{abstract}


theory of literature and comparative literature. Therefore, the essay aims to fill the blank left by Brazilian universities, as they seemed uninterested in following the movements conducted by political leaders in the first decade of this century.

Keywords: global South; humanities; comparative literature; cooperation.

O debate sobre a autonomia ou a filiação da obra de arte a um projeto político tem movimentado a crítica literária por toda a modernidade. Por um lado, a liberdade da literatura é exaltada por autores que ressaltam a impossibilidade de controle da recepção da obra ao longo do tempo, afirmando, como o faz Lyotard, que "é isso que significa ser um artista, um escritor: lançar uma 'mensagem' ao vazio". 1 Por outro, diversos teóricos, especialmente aqueles ligados à tradição marxista, reforçam que o artista deve se preocupar com as formas de mercantilização e com os valores que serão atrelados a seu trabalho. Nos últimos anos, o ressurgimento de discursos de explícita xenofobia e a guinada de vários países para a extrema direita têm alarmado alguns críticos, fazendo com que o debate sobre o compromisso político e social da arte retorne para o centro dos estudos literários a partir de uma interlocução entre projetos políticos e estéticos que sustentam a contemporaneidade. Nessas discussões, ressalta-se como o discurso neoliberal se apropria da defesa da liberdade e da autonomia e tenta justificar falaciosamente o acirramento das desigualdades socioeconômicas como consequências da meritocracia e do respeito às individualidades. A sugestão de vários desses autores é que importantes filósofos da segunda metade do século XX, ao reforçarem a autorreferencialidade da arte e da linguagem, forneceram um escopo teórico que foi indevidamente apropriado por preocupantes tendências da política contemporânea, como a pós-verdade, o individualismo, o empreendedorismo e o descrédito dos direitos humanos e civis.

Escrito em 2012, o livro Literatura comparada e relações comunitárias, hoje, de Benjamin Abdala Júnior, é uma das publicações brasileiras pioneiras no debate sobre a relação entre práticas artísticas e projetos geopolíticos contemporâneos. Sem se aprofundar no debate sobre a integração de teorias pós-estruturalistas a práticas neoliberais, o autor afirma que "desregulamentação e flexibilidade como modelo

1 “[...] c'est cela être un artiste, um écrivain.: lancer um «message» dans le désert." (LYOTARD, Tombeau de l'intellectuel, p. 7, tradução minha). 
para a economia [se tornaram] um desenho 'naturalmente' extensivo às práticas sociais e culturais". ${ }^{2}$ Desde a introdução do livro, Abdala Júnior ressalta as implicações de uma escolha quase unânime das universidades brasileiras por teóricos europeus, capaz de evidenciar o desconhecimento de outras reflexões sobre a contemporaneidade. Em contraposição a essa perspectiva, o autor propõe leituras comparativas de literaturas iberoafro-americanas e analisa produções brasileiras, da América Latina e da África portuguesa. Para justificar sua posição, oposta à prática dominante na academia nacional, ele observa:

Nossa intelectualidade, em geral, tem-se colocado a reboque dos acontecimentos, com discursos legitimadores das hegemonias, voltando-se mais para a administração da diferença nas balizas do sistema estabelecido. E diante das novas solicitações é de se entender que essas vozes da intelectualidade, muitas vezes melancólicas e contemplando ruínas, devem assumir atitudes mais ativas e prospectivas, para criar ou redesenhar, com matização mais forte, tendências de cooperação e solidariedade, que embalaram ideais democráticos. Pelas margens do sistema das assimetrias hegemônicas, abre-se a possibilidade real de se estabelecer efetivos contrapontos ao paroxismo da competitividade, que se coloca como paradigma da vida econômica, social e cultural, de acordo com a lógica dessas assimetrias dos fluxos econômicos e culturais. ${ }^{3}$

Abdala Júnior sugere que os estudos literários acatem a proposta política de construção de blocos transnacionais entre países do Sul global, elaborando análises comparativas de obras desse enorme território geográfico. $\mathrm{O}$ autor observa nesse movimento um escape das hegemonias econômicas e culturais que não apenas validaria a autonomia e os saberes das nações periféricas, mas que também apontaria para possibilidades de ação impossíveis nas relações estabelecidas entre países do Norte e do Sul. Ao reforçar a melancolia com a qual os teóricos brasileiros contemplam as ruínas dos projetos políticos desenhados pela Europa na modernidade, ele indica a dualidade na posição que o país ocupa. Afinal, os projetos de cooperação Sul-Sul desenvolvidos nas últimas

\footnotetext{
${ }^{2}$ ABDALA JÚNIOR. Literatura comparada e relações comunitárias, hoje, p. 9.

${ }^{3}$ ABDALA JÚNIOR. Literatura comparada e relações comunitárias, hoje, p. 10.
} 
duas décadas foram muitas vezes liderados por políticos e embaixadores brasileiros, evidenciando o interesse do país em pautar sua política externa pela cooperação e pela proposição de blocos econômicos e culturais homogêneos. Já a universidade brasileira parece ter ficado à parte desse programa e produziu pouco material teórico sobre as relações institucionalizadas. É inusitado perceber que enquanto a Realpolitik encontrou espaço para ações que subvertem a lógica neoliberal, com a formação de blocos atuantes e transformadores, as humanidades, e especialmente os estudos literários, parecem engessadas em uma perspectiva niilista e descrente, que contempla o fim das narrativas totalizantes sem perceber as possibilidades existentes para além delas. Ao tratar dessa fratura, Abdala Júnior sugere:

O comunitarismo afirma-se, na atualidade, envolvendo pluralidade nas articulações políticas, pautadas sempre pela supranacionalidade. Relevante, nas novas configurações dos antigos desenhos dos sonhos republicanos, é o que já vem ocorrendo, muitas vezes ainda faltando maior empenho: as interlocuções comunitárias como bases para a ação política na forma de blocos, com linhas de ação amplas, da vida econômica à cultural. Blocos politicamente mais eficazes para estabelecer contrapontos às assimetrias dos fluxos hegemônicos supranacionais do novo imperialismo, e também em suas correspondências nacionais e/ou, mesmo, estratificações nacionais. ${ }^{4}$

Ao propor que os estudos literários acompanhem o deslocamento preconizado pelos blocos políticos do Sul global, o teórico prevê mudanças nas temáticas e na forma de abordagem desse campo do saber. Nesse sentido, Abdala Júnior valida perspectivas que ampliem os debates conduzidos pela literatura comparada e promovam uma aproximação entre reflexões teóricas e práticas políticas. Apesar do aparente isolamento do autor em meio aos críticos literários do começo do século XXI, a proposta de Abdala Júnior evidentemente recupera os debates levantados por outros teóricos que pensaram a relação do Brasil com seus pares especialmente na América Latina. Dentre esses trabalhos, é relevante citar aqui o artigo "O entre-lugar do discurso latino-americano", publicado pela primeira vez por Silviano Santiago em 1971, que faz uma severa crítica

\footnotetext{
${ }^{4}$ ABDALA JÚNIOR, Literatura comparada e relações comunitárias, hoje, p. 11.
} 
à relação que os pesquisadores do Brasil estabelecem com a tradição ocidental. Contrapondo-se ao que chama de método hegemônico nas humanidades no país, ele ressalta:

[...] é preciso de uma vez por todas declarar a falência de um método que se enraizou profundamente no sistema universitário: as pesquisas que conduzem ao estudo das fontes ou das influências. Porque certos professores universitários falam em nome da objetividade, do conhecimento enciclopédico e da verdade científica, seu discurso crítico ocupa um lugar capital entre outros discursos universitários. Mas é preciso que agora o coloquemos no seu verdadeiro lugar. Tal tipo de discurso crítico apenas assinala a indigência de uma arte já pobre por causa das condições econômicas em que pode sobreviver, apenas sublinha a falta de uma tradição autóctone, a se apropriar de modelos colocados em circulação pela metrópole. Tal discurso crítico ridiculariza a busca domquixotesca dos artistas latino-americanos, quando acentuam por ricochete a beleza, o poder e a glória das obras criadas no meio da sociedade colonialista ou neocolonialista. Tal discurso reduz a criação dos artistas latino-americanos à condição de obra parasita, uma obra que se nutre de outra sem nunca lhe acrescentar algo de próprio; uma obra cuja vida é limitada e precária, aprisionada que se encontra pelo brilho e pelo prestígio da fonte, do chefe de escola. ${ }^{5}$

Além da importante solução levantada por Santiago nesse ensaio - assumir a impureza e o entre-lugar da cultura latino-americana como potência, e não como cópia -, o autor indica um caminho para os estudos comparatistas em outro texto, escrito mais de 30 anos depois. No artigo "O cosmopolitismo do pobre", publicado na revista Margens / Márgenes da UFMG em 2002, Santiago afirma que a globalização trouxe para as práticas oficiais modelos de parceria que já eram praticados por grupos subalternizados transnacionais, como os dos indígenas sul-americanos, dos sem-terra ou da diáspora africana. Nesse sentido, ele afirma:

${ }^{5}$ SANTIAGO. O entre-lugar do discurso latino-americano, p. 19. 
Ao perder a condição utópica de nação - imaginada apenas pela sua elite intelectual, política e empresarial, repitamos - o estado nacional passa a exigir uma reconfiguração cosmopolita, que contemple tanto seus novos moradores quanto os seus velhos habitantes marginalizados pelo processo histórico. Ao ser reconfigurado pragmaticamente pelos atuais economistas e políticos para que se adeque às determinações do fluxo do capital transnacional que operacionaliza as diversas economias de mercado em confronto no palco do mundo, a cultura nacional estaria (ou deve estar) ganhando uma nova reconfiguração que, por sua vez, levaria (ou está levando) os atores culturais pobres a se manifestarem por uma atitude cosmopolita, até então inédita em termos de grupos carentes e marginalizados em países periféricos. ${ }^{6}$

Contrapondo-se às práticas das chancelarias, que, segundo o autor, apenas reforçavam as hierarquias que estabelecem o espaço geopolítico, as parcerias verdadeiramente cosmopolitas dos grupos marginalizados em países periféricos são capazes de desenhar novas rotas para o cooperativismo em um globo de arranjos estabelecidos pela competitividade. A partir das considerações de Abdala Júnior e de Silviano Santiago, o presente artigo pretende apresentar o conceito de Sul global, mapear algumas propostas que formalizam blocos transnacionais e promover uma aproximação entre pautas estéticas e políticas contemporâneas. Busca-se com isso demonstrar como ações oficiais foram pautadas por governos de países periféricos a partir da mesma lógica que Santiago observa no cosmopolitismo do pobre. Para tanto, serão retomados alguns debates fundamentais para o campo, como a legitimidade de uma produção artística nacional ou regional e a relação entre literatura e realidade. Além disso, esse trajeto pode produzir reflexões importantes sobre o futuro dos estudos literários e das humanidades no Brasil no momento em que a área sofre com acusações contraditórias que ora ressaltam sua inutilidade, ora a responsabilizam por uma formação ideológica dogmática.

É inusitado que as parcerias entre países do Sul tenham acontecido como ações políticas antes de se transformarem em teorias políticosociais. Enquanto a sistematização dos encontros entre os países e a

${ }^{6}$ SANTIAGO. O cosmopolitismo do pobre, p. 59-60. 
formação de blocos teve seu apogeu na primeira década deste século, a produção de livros que debatem a temática é muito mais recente. As principais publicações sobre o Sul global surgiram nos últimos dez anos e grande parte delas, nos últimos três: The Poorer Nations: a History of the Global South (2012), Southern Insurgency: the Coming of the Global Working Class (2016), The Global South Atlantic (2017), South-South Cooperations Beyond the Myths: Rising Donors, New Aid Practices? (2017), Reinventing the Left in the Global South: the Politics of the Possible (2018). Nesse sentido, é possível perceber uma desarticulação entre a prática inicial e a teoria posterior, já que a academia começou a se interessar pela temática do Sul global no momento em que os governos de centro-esquerda perdiam força nesse território e os blocos políticos se enfraqueciam. No período em que o ritmo da história parece atropelar a lentidão necessária para a reflexão, esses estudos ocupam um ponto nodal, no qual tentam entender o contemporâneo a partir da análise do passado recente dos partidos de esquerda em países periféricos e propõem uma possibilidade otimista para o futuro pela parceria entre países historicamente subalternizados. É trágico, porém, que esse pequeno desencontro entre o saber acadêmico e a prática política traga como proposição a nostalgia de um breve momento em que a cooperação surgia como resposta para um mundo estruturado pela competitividade e pelo hiperindividualismo - uma proposta de solidariedade da qual parecemos nos afastar aceleradamente.

Contrapondo-se às teorias agrupadas sob o rótulo de pósmodernidade, os projetos políticos aqui reunidos como representantes das ideias do Sul global demonstram o desejo de somar práticas cotidianas de cooperação e de diálogo a lutas no campo da macropolítica, a partir da formação de partidos, da consolidação de organizações internacionais e da participação efetiva nas instituições mundiais. As propostas dos países do Sul reivindicam a existência de narrativas que sempre estarão fora dos sistemas totalizantes e que rompem com os projetos modernos que almejam a unidade. Ao mesmo tempo, elas evidenciam como a supressão das instituições não promove o fim da violência e das disparidades que conformam o mundo. Nesse sentido, é recorrente que os autores do Sul não demandem a abolição das instituições, mas a transformação de seus preceitos e de suas finalidades. Ao reivindicarem Estados-nação democráticos, interessados em projetos transnacionais e capazes de substituir a lógica do crescimento econômico pelas premissas do bem- 
estar social, do respeito à diferença e da sustentabilidade, esses sujeitos reforçam a interseção entre as práticas macro e micropolíticas e entre as pautas econômicas e identitárias. Além disso, essas cooperações trabalham com o senso de urgência necessário para quem endereça e pretende transformar a conformação violenta, hierárquica e excludente do mundo.

Celso Amorim, em 2006, afirma que os blocos transnacionais do Sul são marcados pelo "signo do pragmatismo", e por isso voltam-se para a "obtenção de avanços concretos", especialmente no combate à pobreza, à fome e ao trabalho infantil, na ampliação do acesso a saúde e educação e na construção de parcerias comerciais bilaterais. Em consonância com o ideal de uma cooperação efetiva, o embaixador declarou que tal projeto "só estará maduro quando transcender os limites das Chancelarias e da esfera governamental. Deve ser um projeto de nossos homens de negócios, de nossos acadêmicos, de nossos jornalistas, enfim, de nossas sociedades." ${ }^{\prime 7}$ Nesse sentido, Amorim evidencia que o trabalho acadêmico e artístico não se opõe à noção de pragmatismo e de urgência que definem a ação dos blocos políticos. Pelo contrário, a escolha por uma lente que focalize preferencialmente as produções e temáticas do Sul pode promover uma revisão na história desses países por evidenciar relações e trocas que passaram despercebidas em projetos marcados pela hierarquia geopolítica. Assim, a validação do Sul global não acontece apenas pela capacidade que esses blocos têm de movimentar a geografia mundial, reposicionando seus agentes, mas também pelo potencial disruptivo de uma narrativa historiográfica incapaz de perceber as idiossincrasias que moldaram a modernidade.

O termo Sul global surge após o fim da Guerra Fria para substituir os conceitos de Primeiro, Segundo e Terceiro Mundos, que até então organizavam o globo em uma topografia obviamente hierarquizada. Ele não representa uma simples mudança de nomenclatura, mas solidifica um projeto de parceria entre países do Sul, autorizando uma releitura da história, tanto geográfica quanto topográfica, e do pós-colonialismo. Por esse motivo, Russel West-Pavlov afirma que "o Sul global não é, pois, meramente um espaço, mas também um período de tempo: o tempo após 1990, no qual o futuro não poderia mais ser concebido acriticamente como

\footnotetext{
${ }^{7}$ AMORIM. Discurso do Ministro das Relações Exteriores, embaixador Celso Amorim, na cerimônia de abertura da reunião ministerial do Fórum de diálogo Índia, Brasil e África do Sul (IBAS).
} 
um lugar de libertação". ${ }^{8}$ Muitos teóricos estabelecem a Conferência de Bandung, realizada em 1955, como o evento formador da ideia do Sul global. A reunião sediada na Indonésia contou com a presença de 29 países da Ásia e da África para pensar em parcerias internacionais capazes de construir uma força política global independente do Norte. No discurso de abertura da conferência, o presidente indonésio Sukarno afirmou que, simultaneamente à geografia vertical que submete as colônias do Sul às metrópoles do Norte, há uma geografia horizontal que aproxima as nações do Sul. Como o presidente indicou, "na maior parte desse gigantesco espaço, os territórios de ambos os lados [do oceano Índico] eram colônias, os povos não eram livres, seus futuros delimitados por um sistema estrangeiro". ${ }^{9}$ Outros autores estipulam a Conferência Tricontinental, realizada em Havana em 1966, como o marco inicial do Sul global por o evento reunir 82 países da Ásia, da África e da América Latina e ter como objetivo declarado a união dessas nações na luta contra o imperialismo. Há ainda aqueles que determinam as propostas apresentadas na Nova Ordem Econômica Internacional (mais conhecida pela sigla em inglês, NIEO), no começo da década de 1970, como o momento em que os países do Sul oficializaram sua parceria ao apresentar na ONU um projeto econômico internacional que favorecesse a região e visasse a reduzir o abismo entre as duas metades do globo.

Em qualquer um desses marcos, fica evidente que o projeto que une os países do Sul não é o de integrar de forma mais ativa o sistema neoliberal e globalizado no qual estão inseridos. Pelo contrário, é nítido que todas essas reuniões propunham um futuro diferente para o mundo a partir da revisão do sistema que legitima o bem-estar de parte da população a partir da miséria da maioria. Mais ainda, está explícito nessas conferências a urgência da revisão da história legitimada, que exclui grande parte do território mundial ou o submete às narrativas da dominação - como acontecia, no momento dessas reuniões, na narrativa progressista de Primeiro, Segundo e Terceiro Mundos, e ainda acontece nos discursos da globalização e do neoliberalismo. Nesse sentido, ainda

\footnotetext{
8 "The Global South is, thus, not merely a space, but also a time: a time after 1990, a time in which the future can no longer be built unproblematically as a site of liberation" (WEST-PAVLOV, The Global South and Literature, p. 12, tradução minha).

9 "For most part of that enormous distance, the territories on both sides of this lifeline were colonies, the peoples were unfree, their future mortgaged to an alien system" (SUKARNO apud WEST-PAVLOV, The Global South and Literature, p. 23, tradução minha).
} 
que as parcerias oficiais entre os países do Sul sejam assustadoramente recentes, os autores demonstram a longínqua cooperação desses territórios e propõem a revisão da história ao evidenciarem que as antigas colônias não estiveram sempre atreladas às determinações das metrópoles. Além disso, é comum que esses teóricos proponham uma releitura da história recente, reforçando, por exemplo, que a Guerra Fria não pode ser narrada como a divisão do mundo em dois blocos coesos. Como eles demonstram, essa estrutura não apenas ignora o domínio dos centros de poder capitalista e socialista sobre os espaços periféricos, mas também desconsidera as disputas existentes no interior de países do Sul, bem como a atuação direta da União Soviética e principalmente dos Estados Unidos nesses conflitos. É por essa razão que Anne Garland Mahler afirma que "como conceito, o Sul global trata da farsa de um suposto triunfo e da fantasiosa inevitabilidade do neoliberalismo na forma com que foi conduzido após o fim da União Soviética". ${ }^{10}$

Ao mesmo tempo, Mahler postula: "o paradoxo central do Sul global: a desregulação e a integração internacional, que são as marcas registradas do neoliberalismo, são as mesmas avenidas pelas quais os movimentos transnacionais de oposição a esse sistema trafegam". ${ }^{11}$ O desafio para as propostas que os blocos apresentam está, portanto, em assumir a multiplicidade e a fluidez (características atribuídas, na economia contemporânea, ao pensamento neoliberal) sem abrir mão da coesão e da parceria como fundamentais para as relações entre sujeitos e nações. Talvez por isso, a bibliografia do Sul global agrupa discursos entusiasmados com a possibilidade de novas organizações internacionais (projetos centrados no bem-estar das pessoas, e não mais no crescimento econômico) e perspectivas desconfiadas, de quem percebe que o século XXI marca apenas a expansão do neoliberalismo e a conformação de países centrais e periféricos também no Sul. As principais organizações intergovernamentais de nações periféricas (BRICS, IBAS, G-15 e NAC) sofrem a acusação de repetirem as estratégias imperialistas nas

\footnotetext{
10 "As a concept, the Global South speaks to the farce of the supposed triumph and inevitability of neoliberalism that was ushered in with the collapse of Soviet communism" (MAHLER, The Global South Atlantic, p. 100, tradução minha).

11 "the central paradox of the Global South: the deregulation and international integration that are the hallmarks of neoliberalism are also the very avenues through which transnational movements of opposition to that system are formed" (MAHLER, The Global South Atlantic, p. 101, tradução minha).
} 
relações político-econômicas que estabelecem com países próximos. Para escaparem dessa queixa, suas assembleias usualmente debatem propostas políticas que substituam o crescimento econômico por práticas de cooperação, de integração social, de valorização da democracia e de distribuição da riqueza. São vários os projetos que representam o sucesso dessa outra forma de cooperação entre países e que elaboram estratégias criativas para promover uma reorganização do fluxo de pessoas e de bens pelo globo. ${ }^{12}$ Paralelamente, outras organizações foram fundadas com a prerrogativa de revisar os valores que definem as relações internacionais, como a ZOPACAS (Zona de Paz e Cooperação do Atlântico Sul), o NAM (Non-Aligned Movement), o CTA (Centro Técnico para la Cooperación Rural y Agrícola de África, el Caribe y el Pacífico) ou o G-77 (Grupo de 77 países do Sul criado para fazer frente ao G-7 na ONU).

É inegável, portanto, o esforço de diversos governos e organizações sociais do Sul global para rever a lógica de dominação que impera nas relações internacionais. Nesse sentido, é fundamental a proposta dessas coalizões por trocar a soberania do território e do progresso pela multiplicidade dos sujeitos e das manifestações culturais, substituindo a competitividade pela cooperação. Para promover uma revisão nos valores que regem a economia neoliberal, tais organizações tentam determinar quais parâmetros são necessários para que a cidadania possa existir em todos os lugares do mundo e promovem coligações que respeitem as diferenças na luta pelo reconhecimento de todos os sujeitos e culturas. Se norte é um termo usado para indicar a singularidade de um destino ou de uma meta, o sul, na visão difundida por esses projetos, representa de fato o seu oposto: um espaço de diversidade e de solidariedade. Assim, os povos do Sul percebem que, apesar das diferenças em suas histórias, culturas e perspectivas, eles compartilham uma história de opressão e de resistência - a condição imposta àqueles que habitam as margens do

${ }^{12}$ Como exemplo, é comum que seja citado o papel central de Índia e Brasil no tratamento da AIDS em países da África, já que ambas as nações burlaram as leis de patente e de distribuição de medicamentos, estabelecidas pelos Estados Unidos e legitimadas pela ONU, para garantir o acesso das drogas à população africana. Vale também mencionar as diversas ações conjuntas de povos indígenas, grupos que lutam pela reforma agrária e coletivos sociais que despontam nesses espaços transnacionais. Além disso, o Fórum Social Mundial, que surgiu em resposta ao Fórum Econômico Mundial de Davos, é um evento importante para a integração das populações do Sul em um projeto político que substitui o crescimento econômico pelo bem-estar da população. 
capitalismo global. E eles assumem também que dividem um projeto comum - uma imaginação política emergente, que sustenta os movimentos contemporâneos - pelo qual as relações sociais estariam submetidas a normas menos sádicas do que aquelas que estão determinadas. Posicionando-se nesse espaço de multiplicidade e de partilha, o Sul global surge como uma resposta à totalidade do Estado-nação e também ao abandono do modelo neoliberal.

Nos estudos literários, porém, a proposta de parcerias entre os países do Sul ainda é bastante incipiente. A primeira publicação a trazer o termo é a revista The Global South, editada pela Indiana University Press desde 2007. Na introdução do segundo exemplar, o editor Alfred López explica seu interesse em trazer para a literatura comparada questões da contemporaneidade que são ignoradas pelo departamento, como o póscolonialismo e os estudos culturais. Com uma dura crítica aos colegas, ele demonstra como a literatura comparada se propõe como o "estudo das diferenças", mas é incapaz de reconhecer as desigualdades que formatam o globo. É por isso que ele termina seu prefácio afirmando que "pode ser banal declarar que todo texto e toda aula são, pelo menos potencialmente, atos políticos. Ainda assim [...] uma disciplina que se vangloria de sua sofisticação intelectual se esqueceu de um de seus pilares básicos". ${ }^{13}$ Entretanto, na edição de abertura, seu texto demonstra como o conceito de política é flutuante. Para apresentar a revista, López determina:

o Sul global é, em suma, sobre aqueles que vivem sob o que Stiglitz chama corretamente de "governança global sem governo global": pessoas muito distantes das maquinarias de poder e de riqueza, pessoas que são impactadas pelas organizações mundiais, mas que não têm chance alguma de responder ou de se fazerem ouvidas. ${ }^{14}$

\footnotetext{
13 "It may seem trite to state that all writing, all teaching is at least potentially a political act. Yet [...] a discipline that has prided itself on its theoretical sophistication has forgotten a basic tent" (LÓPEZ. Introduction: India in a Global Age; or, The Neoliberal Epiphany, p. 11, tradução minha).

14 "The global South, in short, is about those who live under what Stiglitz rightly calls "global governance without global government": people far removed from the machinations of power and wealth, people who are impacted by the policies of world organizations, but have no chance at all to respond and be heard" (LÓPEZ. Introduction: The (Post)global South, p. 2, tradução minha).
} 
Ao ignorar a participação dos países e dos sujeitos do Sul na política global, López deixa indistintos os conceitos de Sul global e de subalternidade. Incapaz de reconhecer a participação desses países nas organizações globais e na proposição de novas formas de política, a revista exibe análises importantes sobre as relações entre Sul e Norte e destaca a desigualdade formadora das relações geopolíticas e sociais a partir de uma perspectiva marcadamente pós-colonial. Apesar disso, o saber e a arte produzidos no Sul seguem sendo validados a partir dos critérios e das teorias canonizadas.

Francisco Foot-Hardman, no artigo "Ilusões geográficas sobre a volubilidade da noção de periferia no espaço-tempo global", ataca frontalmente a proposição do termo Sul global pelas humanidades no Brasil ao afirmar que

a aposta no "excepcionalismo" dos hoje rotulados países e regiões do "Sul global" parece ser um dos últimos recursos acadêmicos de socorro mútuo para salvar as "diferenças" das representações literárias, artísticas e culturais de sua liquefação no espaço comum do fetiche hiperinflacionado da civilização tecnológica capitalista. Tal operação, no que tem de excessiva, parece antecipar, dialeticamente, sob o reino da "sociedade do espetáculo," o declínio inevitável da diversidade cultural e estética, em meio ao colapso socioambiental planetário e caoticamente expandido, pelo menos desde a segunda metade do século XX, em processo conhecido como a "grande aceleração" e que inaugurou nova era geológica, o Antropoceno, cuja existência, determinação e efeitos são hoje passíveis de mais do que razoável consenso científico. ${ }^{15}$

Tratando o termo como parte do fetiche das universidades norte-americanas por inventarem novos conceitos e tentarem explicar a realidade dos países periféricos, Foot-Hardman afirma que sua assimilação por nossos pesquisadores aparece como reforço de nossa subalternidade. A principal crítica do autor, como está evidente na citação acima, está na oposição entre os parâmetros que julgam valores políticos e econômicos e aqueles que validam manifestações culturais. Em outro trecho, o autor reforça:

\footnotetext{
${ }^{15}$ FOOT-HARDMAN. Ilusões geográficas sobre a volubilidade da noção de periferia no espaço-tempo global, p. 6.
} 
Parece, em geral, que o excepcionalismo do periférico é sempre motivo de rebaixamento no que diz respeito à economia e à institucionalidade da política, mas, ao mesmo tempo, fonte de rejúbilo nos domínios das culturas autóctones, das artes e da literatura. Esquecendo-se que tal movimento nada mais é do que refolclorização do pitoresco, do primitivo, do popular no lance de sua domesticação e consagração no inventário do nacional, o modernismo paulista inaugurado em 1922 foi a narrativa hegemônica de melhor performance sob pretexto de resgate. ${ }^{16}$

Evidentemente, a perspectiva apresentada neste artigo não define o Sul global da mesma forma que Foot-Hardman. Pelo contrário, a escolha por trazer para os estudos culturais um termo estabelecido em práticas políticas, diplomáticas e econômicas recentes busca aproximar as humanidades - especialmente os estudos literários - dos debates que circunscrevem o espaço geopolítico. Recusando a folclorização, que pode, de fato, ser percebida em publicações norte-americanas sobre o Sul global, o projeto aqui delineado não objetiva definir características comuns que permitissem englobar toda a produção literária de um hemisfério. Pelo contrário, trata-se do reconhecimento da multiplicidade e da impossibilidade de cerceamento do espaço em fronteiras artificiais. Em consonância com parcerias que sempre aconteceram nesses lugares e foram incorporadas à política oficial no começo deste século, a crítica literária do Sul global seria marcada pelo interesse em desviar o olhar das formas canonizadas de comparatismo (cuja estrutura da influência ou do modelo/cópia é o principal expoente) e buscar por diálogos que já acontecem nas produções culturais de povos e países periféricos.

Oposta à perspectiva atacada por Foot-Hardman está também o único livro de literatura comparada a tratar do Sul global, The Global South and Literature (2018), organizado por Russel West-Pavlov e que se propõe a apresentar a "circulação transnacional de influências culturais, traçando suas manifestações pelas tradições de África, Ásia e América Latina". ${ }^{17}$ A publicação analisa comparativamente produções literárias

${ }^{16}$ FOOT-HARDMAN. Ilusões geográficas sobre a volubilidade da noção de periferia no espaço-tempo global, p. 10.

17 "The Global South and Literature explores the historical, cultural and literary applications of the term for 21 st century flow of transnational cultural influence, tracing their manifestations across the global Southern traditions of Africa, Asia and Latin America" (WEST-PAVLOV. The Global South and Literature, p. 1, tradução minha). 
dos três continentes, reformulando a historiografia ao evidenciar como centenas de anos (ou mesmo milênios) marcam fluxos migratórios, trocas econômicas e coalizões políticas em territórios do Sul. O livro é, portanto, uma produção meta-analítica, que busca apresentar o conceito de Sul global e demonstrar sua eficácia na análise de diversos textos produzidos nesse hemisfério. Sem ressaltar a vinculação desse projeto aos blocos políticos transnacionais, os autores reforçam a importância dessas parcerias para a autonomia da região e para o fim de um discurso de colonização ou de subdesenvolvimento que sempre atrela o Sul aos critérios já legitimados.

A escolha pela meta-análise, comum ao livro de West-Pavlov e aos poucos artigos publicados na área, é natural para a consolidação do campo e existe em resposta às práticas comparatistas que parecem desconhecer a possibilidade de se produzir análises que escapem da literatura e da teoria do Norte. Apesar disso, é importante que a ideia do Sul global se desloque de uma produção sempre meta-analítica para que possa existir como uma prática cotidiana e interessada nos aspectos estéticos, nas estratégias discursivas e/ou nas implicações políticas dos textos. Mais ainda, como Dilip Menon afirma em seu artigo "Thinking About Global South: Affinity and Logic", o projeto será ineficaz caso se transforme em uma tentativa de validação das correntes filosóficas hegemônicas através de exemplos do Sul. Como o autor ressalta, é fundamental que também as teorias e as proposições político-sociais de autores dos países periféricos passem a circular pelas universidades. Diz Menon:

Eu acredito que pensar sobre o Sul global (suas tradições intelectuais, suas categorias conceituais e sua miscigenação com a genealogia das ideias ocidentais) é um projeto do qual nós precisamos, mas no qual ainda não embarcamos. Nós temos desenvolvido a iniciativa de pensar a partir do Sul global, o que tem significado, como no caso da teoria pós-colonial, a reiteração de uma epistemologia europeia, meramente feita da nossa localidade. ${ }^{18}$

\footnotetext{
18 "I believe that thinking about the global South (its traditions of intellection, its conceptual categories, and the miscegenated genealogy of Western ideas) is a project that we need to, but have not yet embarked upon. We have been through the enterprize of thinking from the global South, which has meant, as in the case of postcolonial theory, the reiteration of a European episteme, but merely from our location" (MENON. The Global South and Literature, p. 38, tradução minha, grifos do autor).
} 
Como diversos autores demonstram ao longo do livro, mesmo quando as literaturas do Sul são objetos de pesquisa, suas análises seguem sendo feitas a partir da teoria produzida e dos valores determinados pela Europa e pelos Estados Unidos. Uma análise nos departamentos de estudos literários brasileiros provavelmente confirmaria essa hipótese. Como Benjamin Abdala Júnior indica, a ampliação do acesso à universidade e à pós-graduação nas duas últimas décadas não produziu uma comunidade de teóricos brasileiros reconhecidos internacionalmente. Mais ainda, a consolidação da literatura comparada no país pouco tem feito para ampliar as relações socioculturais do Brasil com outros países do Sul. Pelo contrário, é comum que as publicações e as parcerias entre universidades ressaltem uma lógica de subdesenvolvimento, que segue buscando a validação das instituições tidas como centrais. Além disso, os poucos trabalhos de literatura comparada fora do eixo Brasil-Europa/ Estados Unidos comumente tratam de uma estética latino-americana ou das semelhanças entre a produção dos países falantes de português. Em ambos os casos, porém, exalta-se uma comunidade na qual a posição do Brasil é periférica: os demais países latino-americanos e a comunidade de nações africanas falantes de português compartilham mais características linguísticas, culturais e históricas entre si do que com o Brasil. E mesmo essas produções são pouco estimuladas pelos departamentos de literatura das universidades brasileiras, como se pode ver pela escassez de produções e de intercâmbios entre os países. Sem negar a importância dessas comunidades, o Sul global permite pensar nas parcerias que o Brasil estabelece com nações que não compartilham o mesmo espaço geográfico ou a mesma língua, mas que se mobilizam por questões sociais ou por princípios estéticos semelhantes.

Mais uma vez, a proposta do Sul global não é por circunscrever o maior hemisfério do globo a uma unidade. Nos estudos literários, pensar nessa comunidade não significaria perceber traços estéticos ou temáticas capazes de abranger toda a produção dessa gigantesca região. O projeto - ainda mais ousado - inclui a revisão do conceito de unidade e a validação da multiplicidade como elemento determinante de um bloco. Assumindo, a partir de Benedict Andersen, que a nação é uma comunidade imaginada, a proposta defendida por esses autores prevê o diálogo como premissa e assume a impossibilidade de totalização. Trata-se, portanto, de um investimento consciente dos intelectuais dos países do Sul em promoverem análises comparativas entre algumas produções literárias 
e teóricas, sem a ilusão de que toda a produção artística de uma região geográfica cumpriria critérios estéticos comuns. Afinal, a hipótese de um cânone universal imparcial e afastado das conformações geográficas do mundo, que faria circular as obras de maior qualidade literária, já foi amplamente desmascarada pela teoria da literatura, mas continua ecoando nas práticas das universidades e das editoras. Sem um investimento para que os leitores busquem pelas produções de outros espaços, a literatura segue tratando a produção dos países centrais (da Europa e dos Estados Unidos) como definidora de tendências que ressoam ao redor do globo. Nesse sentido, a ampliação da leitura a partir de critérios geográficos já é uma justificativa para se investir no projeto. Junto a isso, a busca por outros teóricos evidencia as mitologias que formalizaram a modernidade e abre possibilidades para se pensar em um futuro alternativo no momento em que a realidade política caminha para a anulação de princípios fundamentais do humanismo moderno, como o reconhecimento dos direitos humanos e civis, enquanto a melancolia e o niilismo limitam as reflexões das humanidades. Na contramão dessa postura, a arte e a política do Sul global se recusam lamentar as ruínas de monumentos que nunca lhes pertenceram. Ao invés da melancolia pelo fim de uma ideia de unidade e de progresso, esses teóricos estão interessados em construir uma comunidade consciente da violência da totalização e disposta a integrar diferenças. Nesse sentido, o descompasso entre o momento atual e aquele em que a política internacional do Brasil se pautava pela cooperação Sul-Sul não invalida a escolha pelo comparatismo entre países periféricos. Pelo contrário, em oposição a escolhas políticas que descaracterizam nosso ideal de justiça, o Sul global pode se manter como um projeto de integração entre países diversos, tendo por base o reconhecimento de nossas condições históricas, geográficas, políticas e sociais e almejando um futuro - talvez utópico - em que as relações entre os povos seriam marcadas pela cooperação e pelo respeito.

\section{Referências}

ABDALA JÚNIOR, Benjamin. Literatura comparada e relações comunitárias, hoje. São Paulo: Ateliê Editorial, 2012.

AMORIM, Celso. Discurso do Ministro das Relações Exteriores, embaixador Celso Amorim, na cerimônia de abertura da reunião ministerial do Fórum de diálogo Índia, Brasil e África do Sul (IBAS). [S. l.]: Ministério 
das Relações Exteriores, 2006. Disponível em: http://www.itamaraty.gov. $\mathrm{br} / \mathrm{pt}$-BR/discursos-artigos-e-entrevistas-categoria/7818-discurso-doministro-das-relacoes-exteriores-embaixador-celso-amorim-na-cerimoniada-abertura-da-reuniao-ministerial-do-forum-de-dialogo-india-brasil-eafrica-do-sul-ibas. Acesso em: 22 jan. 2019.

FOOT-HARDMAN, Francisco. Ilusões geográficas sobre a volubilidade da noção de periferia no espaço-tempo global. Letterature d'America, Roma, v. 161, p. 5-18, 2016.

LÓPEZ, Alfred. Introduction: India in a Global Age; or, The Neoliberal Epiphany. The Global South, Bloomington, n. 1, v. 2, 2008, p. 1-10. DOI: https://doi.org/10.2979/GSO.2008.2.1.1.

LÓPEZ, Alfred. Introduction: The (Post)global South. The Global South. Bloomington, n. 1, v. 1, 2007, p. 1-11. DOI: https://doi.org/10.2979/ GSO.2007.1.1.1.

LYOTARD, Jean-François. Tombeau de l'Intellectuel. In:

Tombeau de l'Intellectuel et autres papiers. Paris: Edition Galilée, 1984. p. 3-7.

MAHLER, Anne-Garland. Beyond the Color Curtain: the Metonymic of Color Politics in the Tricontinental and the New Global South. In: BRYSTON, Kerry; SLAUGHTER, Joseph. The Global South Atlantic. Nova York: Fordham University Press, 2017. p. 100-118. DOI: https:// doi.org/10.5422/fordham/9780823277872.003.0006.

SANTIAGO, Silviano. O cosmopolitismo do pobre. In: O cosmopolitismo do pobre. Belo Horizonte: Editora UFMG, 2008. p. 45-63.

SANTIAGO, Silviano. O entre-lugar do discurso latino-americano. In: Uma literatura nos trópicos. Recife: Editora CEPE, 2019. p. 9-30.

WEST-PAVLOV, Russel (ed.). The Global South and Literature. Cambridge: Cambridge University Press, 2018. DOI: https://doi. org/10.1017/9781108231930. 